\title{
Influence of placental position on obstetric morbidity in placenta previa
}

\author{
Shripad S. Hebbar*, Lavanya Rai, Rubina Zainab, \\ Shyamala Guruvare, Prashanth Adiga, Anjali Mundkur
}

Department of Obstetrics \& Gynaecology, KMC, Manipal University, Manipal, Karnataka, India

Received: 18 June 2014

Accepted: 5 July 2014

*Correspondence:

Dr. Shripad S. Hebbar,

E-mail: drshripadhebbar@yahoo.co.in

(C) 2014 Hebbar SS et al. This is an open-access article distributed under the terms of the Creative Commons Attribution Non-Commercial License, which permits unrestricted non-commercial use, distribution, and reproduction in any medium, provided the original work is properly cited.

\begin{abstract}
Background: In placenta previa, the placenta occupies lower uterine segment and is likely to separate during pregnancy, resulting in significant maternal and perinatal morbidity and mortality. It has been well studied as the degree of placenta previa increases, the risk of bleeding also increases. However, there are few studies regarding configuration of placenta in relation to uterine wall (anterior, posterior or lateral) and associated complications. The primary purpose of this retrospective cohort study is to examine the whether the location of placenta in relation to lower uterine segment during caesarean delivery influences development of bleeding complications necessitating various surgical interventions. The secondary objective was to study various factors such as preterm delivery, fetal growth restriction, perinatal deaths and postpartum haemorrhage in relation to location of placenta.

Methods: We conducted a retrospective study of 89 patients with placenta previa with ultrasonographically mapped placenta over a period of 5 years. The subjects were further categorized into anterior, posterior and lateral group depending upon location of placenta in relation to uterine wall. Differences between age, parity, history of previous caesarean delivery, antepartum haemorrhage, preterm deliveries, foetal growth restriction, perinatal deaths, operative complications and surgical interventions, placenta accreta and postpartum haemorrhage were studied and also were compared to traditional classification of placenta previa in relation to internal cervical ostium. The statistical analysis of the data was performed according to Pearson Chi-square test, one way ANOVA test using SPSS Software.

Results: The overall incidence of placenta previa was $1.01 \%$. Placental location was anterior in 23 women (25.8\%), posterior in 49 women $((55 \%)$ and lateral in $17(19.1 \%)$. No significant differences were found in these groups regarding age, gestational age at delivery, parity, previous history of caesarean delivery, incidence of antepartum and postpartum haemorrhage. Need for surgical interventions such as uterine artery ligation, internal iliac artery plication, caesarean hysterectomy was not specific any type of placenta previa. $39.1 \%$ of anterior, $40 \%$ of posterior and $35.2 \%$ of lateral placenta previa received blood component therapy and this variation was not statistically significant. The overall perinatal mortality was 45/1000 live births and mortality rate did not vary significantly in any of the groups.

Conclusions: It is difficult to assign a maternal or perinatal morbidity risk to a particular type of placental location. The need for specialized surgical intervention such as uterine / internal iliac artery ligation, peripartum hysterectomy can arise irrespective of placental location, whether underneath the surgical incision (anterior), proximity to main uterine trunks (lateral) or encountered after the delivery of the baby (posterior). Pregnancies complicated by placenta previa must be delivered in the hospitals having expertise of senior and skilled surgeons and well equipped blood bank and good neonatal intensive care unit.
\end{abstract}

Keywords: Placenta previa, Caesarean hysterectomy, Placenta accreta, Placental location 


\section{INTRODUCTION}

Normally the placenta occupies upper uterine segment and gets separated and expelled following the birth of the baby. Placenta previa is a form of defective development where placenta lies in lower uterine segment and is prone for separation during pregnancy resulting in antepartum haemorrhage. Many a times, emergency operative delivery is only the choice when there is profuse haemorrhage, even if the pregnancy is remote from term. There is also a higher chance of postpartum haemorrhage as lower segment unlike upper segment, poorly contracts and effective haemostasis is not achieved. Hence placenta praevia is associated with significantly higher maternal and perinatal mortality and morbidity. The etiology of placenta praevia remains uncertain and is associated with multiple risk factors such as high parity, history of previous spontaneous or induced including cesarean section, abortions, number of previous cesarean sections, previous uterine operations, previous placenta previa, smoking or substance abuse during pregnancy, multiple gestation, male sex of the newborn.

Placenta previa is classified mainly into four types (Type 1: placenta just encroaches into lower uterine segment and much away from internal os, type 2: placenta extends up to margin of internal os, type 3: portion of the placenta covers the internal os, type 4: entire placenta covers the internal os) and it is generally believed that higher the grade, higher the risk of antepartum and postpartum haemorrhage. Paradoxically type 4 placenta if associated with morbidly adherent placenta may not bleed at all during pregnancy. The surgeons performing caesarean delivery for anterior placenta are always worried as placenta lies beneath the incision site and there is a risk of significant brisk haemorrahge before extraction of the baby. On the contrary, posterior placenta may prove troublesome because it may be difficult to control bleeding from the posterior uterine wall because of anatomical inaccessibility. There are very few publications regarding these issues and the present study examines the influence of position of placenta (anterior, posterior and lateral) with regard to obstetric haemorrhage, in addition to traditional grading of placenta praevia.

\section{Aims and objectives}

We wanted to verify following hypotheses in placenta previa.

- Greater amount of blood loss is expected as grading of placenta previa increases.

- Anterior placenta previa lies beneath the incision site during caesarean section and hence more bleeding may occur.

- Lateral placenta previa is likely to bleed more due to proximity to uterine vessels.
- Posterior placenta previa is likely to bleed more intra - operatively due to limited surgical access to posterior uterine wall.

In addition, we wanted to compare various maternal and perinatal factors such as incidence of obstetric haemorrhage (both antepartum and postpartum), morbidly adherent placenta (placenta accreta), need for special surgical interventions such as major arterial ligation procedures (uterine and internal iliac artery), caesarean hysterectomy, preterm delivery rates, incidence of foetal growth restriction and perinatal deaths in these groups. The same outcome measures were simultaneously studied according to traditional 4 groups classifications (Type 1 to 4 ).

\section{METHODS}

This was a retrospective observational study conducted in the department of obstetrics and gynaecology in a medical college hospital in costal Karnataka for a 5 year period (2007 to 2012). Institutional ethical committee approved the study. There were a total of 8809 deliveries in this period and number of placenta previa accounted for 89 cases. All of the patients had ultrasonographic evaluation of placental position.

Primary outcome measures studied were incidence of antepartum hemorrhage (APH), postpartum haemorrhage $(\mathrm{PPH})$. We defined postpartum haemorrhage as blood loss of $>1000 \mathrm{ml}$ during caesarean delivery or when there was a need for blood component therapy. We also studied surgical interventions for PPH and perinatal morbidity and mortality.

Data analysis was performed on SPSS (Statistical Package for Social Sciences, version 16, for windows). The variables were categorized as discrete and continuous. Frequencies and mean were calculated for continuous variables and proportions were reported for discrete variables. The statistical analysis of the data was performed according to Pearson Chi-square test (categorical variable), one way ANOVA test (numerical variable). A P value of $<0.05$ was considered significant.

\section{RESULTS}

There were total of 89 cases of placenta previa among 8809 deliveries. According to this, the prevalence of placenta previa was 1 in 99 deliveries $(1.01 \%)$. Of these 44 cases had antepartum haemorrhage $(49.4 \%)$ and 31 had postpartum haemorrhage (34.8\%). These cases were analysed for their association with placental location, degree of placenta previa, adherent placenta, surgical interventions and perinatal outcome.

We defined placenta previa as anterior when major portion of the placenta was visualized beneath anterior LS (lower uterine segment) using partially filled bladder to demarcate LS. When the majority of the placental 
substance was visualized posteriorly, we considered it as posterior placenta previa. Lateral placenta previa was diagnosed when placenta was seen mainly to either left or right side with equal distribution both anteriorly and posteriorly. We observed that posterior placentation was most common (55\%), followed by anterior $(25.8 \%)$ and lateral $(19.1 \%)$

Table 1 shows patient characteristics according to these positions.

Table 1: Patient characteristics in 3 types of placental locations.

\begin{tabular}{|c|c|c|c|c|}
\hline Parameter & $\begin{array}{l}\text { Anterior } \\
(\mathbf{n}=\mathbf{2 3})\end{array}$ & $\begin{array}{l}\text { Posterior } \\
(n=49)\end{array}$ & $\begin{array}{l}\text { Lateral } \\
(\mathrm{n}=17)\end{array}$ & P value \\
\hline $\begin{array}{l}\text { Age } \\
\text { (years) }\end{array}$ & 27.7 & 28.4 & 29.1 & $0.64 *$ \\
\hline $\begin{array}{l}\text { Gestational } \\
\text { age at first } \\
\text { bout of } \\
\text { bleeding } \\
\text { (weeks)\# }\end{array}$ & 33.1 & 33.8 & 33.7 & $0.59 *$ \\
\hline $\begin{array}{l}\text { Gestational } \\
\text { age at } \\
\text { delivery } \\
\text { (weeks) }\end{array}$ & 36 & 37 & 36 & $0.77 *$ \\
\hline $\begin{array}{l}\text { Parity } \\
\text { (mean) }\end{array}$ & 1.6 & 1.7 & 1.5 & $0.75^{*}$ \\
\hline $\begin{array}{l}\text { Multiple } \\
\text { pregnancy } \\
(\mathrm{n}=2)\end{array}$ & 1 & 1 & 0 & $0.63 * *$ \\
\hline $\begin{array}{l}\text { Adherent } \\
\text { placenta } \\
(\mathrm{n}=5)\end{array}$ & 0 & 5 & 0 & $0.30 * *$ \\
\hline $\begin{array}{l}\text { Previous } \\
\text { LSCS } \\
(\mathrm{n}=9)\end{array}$ & 2 & 5 & 2 & $0.90 * *$ \\
\hline \multicolumn{5}{|c|}{$\begin{array}{l}* \text { One Way ANOVA, } * * \text { Chi square test } \\
\text { \#patients with antepartum haemorrhage, anterior } 13 \text {, posterior } \\
22 \text {, lateral } 9\end{array}$} \\
\hline
\end{tabular}

We defined any amount of vaginal bleeding whether warning or brisk haemorrhage as antepartum haemorrhage (APH) when it occurred prior to delivery. All of our patients had caesarean deliveries. Bleeding that occurred at the time of caesarean delivery when estimated blood loss was in access of $1000 \mathrm{ml}$ was considered as postpartum haemorrhage $(\mathrm{PPH})$. We also considered postoperative cases as PPH group when they exceeded $500 \mathrm{ml}$ of blood loss.

Table 2 shows incidence of obstetric haemorrhage (both APH and PPH) in different placenta previa groups according to the position of the placenta in relation to uterine wall. It can be seen that almost half of the patients had APH and one third of them had PPH. None of the groups had statistically higher incidence of either APH or PPH.
Table 2: Relation between location of placenta and incidence of obstetric haemorrhage.

\begin{tabular}{|c|c|c|c|c|}
\hline $\begin{array}{l}\text { Location of } \\
\text { placenta }\end{array}$ & $\begin{array}{l}\text { Cases with } \\
\text { APH n }(\%)\end{array}$ & $\begin{array}{l}\text { P } \\
\text { value }\end{array}$ & $\begin{array}{l}\text { Cases with } \\
\text { PPH n }(\%)\end{array}$ & $\begin{array}{l}P \\
\text { value }\end{array}$ \\
\hline $\begin{array}{l}\text { Anterior } \\
\text { placenta } \\
\text { previa }(n=23)\end{array}$ & $13(56.5)$ & \multirow{3}{*}{0.62} & $7(30.4)$ & \multirow{3}{*}{0.87} \\
\hline $\begin{array}{l}\text { Posterior } \\
\text { placenta } \\
\text { previa }(n=49)\end{array}$ & $22(44.9)$ & & $18(36.7)$ & \\
\hline $\begin{array}{l}\text { Lateral } \\
\text { placenta } \\
\text { previa }(n=17)\end{array}$ & $9(52.9)$ & & $6(35.3)$ & \\
\hline
\end{tabular}

Patients were also categorized as type 1 to type 4 depending upon their relation to internal os which is the standard classification known to all obstetric community. Though both APH \& PPH incidence increased as the grading increased, the variation did not reach statistical significance.

Table 3 shows incidence of obstetric haemorrhage (both $\mathrm{APH}$ and $\mathrm{PPH}$ ) in placenta previa according to type.

Table 3: Relation between location of placenta and incidence of obstetric haemorrhage.

\begin{tabular}{|c|c|c|c|c|}
\hline $\begin{array}{l}\text { Location of } \\
\text { placenta }\end{array}$ & $\begin{array}{l}\text { Cases with } \\
\text { APH n }(\%)\end{array}$ & $\begin{array}{l}\mathbf{P} \\
\text { value }\end{array}$ & $\begin{array}{l}\text { Cases with } \\
\text { PPH n }(\%)\end{array}$ & $\begin{array}{l}\mathbf{P} \\
\text { value }\end{array}$ \\
\hline $\begin{array}{l}\text { Type I } \\
(\mathrm{n}=24)\end{array}$ & $10(41.7)$ & \multirow{4}{*}{0.63} & 7 (29.2) & \multirow{4}{*}{0.10} \\
\hline $\begin{array}{l}\text { Type II } \\
(\mathrm{n}=23)\end{array}$ & $11(47.8)$ & & $8(34.8)$ & \\
\hline $\begin{array}{l}\text { Type III } \\
(\mathrm{n}=33)\end{array}$ & $17(51.5)$ & & $12(36.4)$ & \\
\hline $\begin{array}{l}\text { Type IV } \\
(\mathrm{n}=09)\end{array}$ & $6(66.7)$ & & $4(44.4)$ & \\
\hline
\end{tabular}

All the operative deliveries were performed by senior faculty. Adequate amount of blood components were kept cross matched and were issued on demand. Six of the patients required bilateral uterine bleeding for control of bleeding and no further devascularisation was required in them. Two patients had uncontrollable postpartum haemorrhage on the table even after bilateral internal iliac artery ligation and hence underwent caesarean hysterectomy.

There were 5 cases of adherent placenta. All were posteriorly located. All were type IV placenta previa. In the all cases, placenta could be delivered piecemeal during caesarean section and none of them required hysterectomy.

Type of intervention, need for blood component transfusion is shown in Table 4 in detail. 
Table 4: Type of intervention in relation to position and type of placenta previa.

\begin{tabular}{|lllllllllll|}
\hline Intervention & $\begin{array}{l}\text { Anterior } \\
\text { placenta } \\
(\mathbf{2 3})\end{array}$ & $\begin{array}{l}\text { Posterior } \\
\text { placenta } \\
(49)\end{array}$ & $\begin{array}{l}\text { Lateral } \\
\text { placenta } \\
(\mathbf{1 7})\end{array}$ & Significance & $\begin{array}{l}\text { Type I } \\
(\mathbf{2 4})\end{array}$ & $\begin{array}{l}\text { Type II } \\
(\mathbf{2 3})\end{array}$ & $\begin{array}{l}\text { Type III } \\
(\mathbf{3 3})\end{array}$ & $\begin{array}{l}\text { Type IV } \\
(\mathbf{9})\end{array}$ & Significance \\
\hline $\begin{array}{l}\text { Uterine artery } \\
\text { ligation (n=6) }\end{array}$ & 2 & 3 & 1 & $\#$ & 1 & 1 & 2 & 2 & $\#$ \\
\hline $\begin{array}{l}\text { Internal Iliac artery } \\
\text { ligation (n=2) }\end{array}$ & 0 & 2 & 0 & $\#$ & 0 & 0 & 0 & 2 & $\#$ \\
\hline $\begin{array}{l}\text { Caesarean } \\
\text { hysterectomy (n=2) }\end{array}$ & 0 & 2 & 0 & $\#$ & 0 & 0 & 0 & 2 & $\#$ \\
\hline $\begin{array}{l}\text { Blood component } \\
\text { therapy (n=35) }\end{array}$ & 9 & 20 & 6 & 0.92 & 7 & 8 & 13 & 7 & 0.07 \\
\hline \#Statistical tests could not be applied as the number was small & & & & & & & \\
\hline
\end{tabular}

Table 5 shows perinatal outcome in relation to position and type of placenta previa. The mean birth weight in all the groups was lower than $2.5 \mathrm{~kg}$. Though it appeared that preterm delivery and intrauterine growth restriction occurred more frequently in lateral placenta, no statistical significance could be attached because of the smaller number patients in this group. There were 3 intrauterine deaths and one early neonatal death in our series. The perinatal mortality was $45 / 1000$ live births.

Table 5: Perinatal outcome in relation to position and type of placenta previa.

\begin{tabular}{|llllllllll|}
\hline Outcome & $\begin{array}{l}\text { Anterior } \\
\text { placenta } \\
(\mathbf{2 3})\end{array}$ & $\begin{array}{l}\text { Posterior } \\
\text { placenta } \\
(49)\end{array}$ & $\begin{array}{l}\text { Lateral } \\
\text { placenta } \\
(\mathbf{1 7})\end{array}$ & $\begin{array}{l}\text { Signi- } \\
\text { ficance }\end{array}$ & $\begin{array}{l}\text { Type I } \\
(\mathbf{2 4})\end{array}$ & $\begin{array}{l}\text { Type II } \\
(\mathbf{2 3})\end{array}$ & $\begin{array}{l}\text { Type III } \\
(\mathbf{3 3})\end{array}$ & $\begin{array}{l}\text { Type IV } \\
(\mathbf{9})\end{array}$ & $\begin{array}{l}\text { Signi- } \\
\text { ficance }\end{array}$ \\
\hline $\begin{array}{l}\text { Birth weight in } \\
\text { Kg (Mean } \pm \text { SD) }\end{array}$ & $2.4 \pm 0.75$ & $2.3 \pm 0.59$ & $2.2 \pm 0.05$ & $\mathrm{NS}$ & $2.4 \pm 0.24$ & $2.3 \pm 0.43$ & $2.2 \pm 0.14$ & $2.2 \pm 0.38$ & $\mathrm{NS}$ \\
\hline Preterm (n, \%) & $11(47.8)$ & $22(44.9)$ & $9(52.9)$ & 0.84 & $11(45.8)$ & $11(47.8)$ & $15(45.5)$ & $5(55.6)$ & 0.95 \\
\hline IUGR (n, \%) & $6(26.1)$ & $10(20.4)$ & $8(47.1)$ & 0.10 & $7(29.2)$ & $6(26.1)$ & $8(24.2)$ & $3(33.3)$ & 0.94 \\
\hline $\begin{array}{l}\text { Intra uterine } \\
\text { deaths (n =3) }\end{array}$ & 0 & 2 & 1 & $*$ & 0 & 0 & 2 & 1 & $*$ \\
\hline $\begin{array}{l}\text { Neonatal deaths } \\
(\mathrm{n}=1)\end{array}$ & 1 & 0 & 0 & $*$ & 0 & 0 & 0 & 1 & $*$ \\
\hline
\end{tabular}

\section{DISCUSSION}

Placenta previa and abruptio placenta are the two important causes for antepartum haemorrhage and all those who have significant antepartum haemorrhage are also likely to have postpartum haemorrhage. However, clinical courses widely vary with each patient. Some patients require preterm cesarean delivery and hysterectomy for life-threatening hemorrhage / adherent placenta, whereas others undergo elective cesarean section at term without hemorrhagic complications.

It is generally believed that risk of antepartum haemorrhage rises with increasing degree of placenta previa. However there are contradicting reports in this aspect in the literature. Dola \& Garite et al., ${ }^{1}$ Bhide and Prefumo et al. ${ }^{2}$ have reported a significantly higher rate of antepartum haemorrhage with increasing degrees of placenta previa. In other studies, however, no statistically significant association was seen in incidence of obstetric haemorrhage according to the degree of placenta previa. $^{3,4}$

In our study, the incidence of antepartum haemorrhage gradually rose as degree of placenta previa increased, but did not reach statistical significance. And interestingly $48.5 \%$ of Type III and $32.3 \%$ of Type IV placenta previa did not have any bleeding episode till delivery. It is difficult, therefore, to predict whether or not an individual patient with placenta previa is going to bleed according to type of placenta previa.

Atsuko Sekiguchi et al. ${ }^{5}$ conducted a retrospective study on 162 women who were diagnosed to have placenta previa and studied the need for emergency caesarean delivery for torrential vaginal bleeding in incomplete and complete placenta previa. The diagnosis of placenta previa was done by transvaginal ultrasound by a trained 
physician. They defined complete placenta previa was defined as a placenta that completely covered the internal cervical os with one of the placenta margins was at least $2 \mathrm{~cm}$ away from internal os. Incomplete placenta previa was defined as when the placenta partially covered the internal os, but the placental margin was situated within 2 $\mathrm{cm}$ of the internal os. The incidence of antepartum haemorrhage was significantly higher in complete placenta previa compared to incomplete placenta previa (59.1\% versus $17.6 \%$ ). They further divided each group into two, depending upon the location of placenta; both anterior and posterior. In complete placenta previa, incidence of antepartum hemorrhage did not significantly differ between the anterior and the posterior groups (76.2\% vs. $54.0 \%$ in complete placenta previa and $20.0 \%$ vs. $17.3 \%$ in incomplete placenta previa). We too observed higher incidence of antepartum haemorrhage in major degree (type $3 \& 4$ ) placenta previa (54.7\%) compared to minor degree (type $1 \& 2$ ) placenta previa $(44.6 \%)$ though statistically not significant. Similar to their findings, the position of placenta in our study did not influence incidence of antepartum haemorrhage.

It was our observation that the incidence of posterior placenta previa was more compared to other positions. This phenomenon is probably due to the fact that placental tissue preferentially develops on the posterior uterine wall in placenta previa. A previous study reported that the incidence of placental migration is higher and the migration rate is faster in women with anterior placenta previa. $^{6}$

Other contributory factors speculated responsible for anterior placenta previa are multiparity and history of more than two cesarean sections. ${ }^{7}$ In our study, the mean parity was lesser than 2 in all three placental positions and only $10.1 \%$ of patients had previous caesarean deliveries.

In our study, $39.1 \%$ of anterior, $40 \%$ of posterior and $35.2 \%$ of lateral placenta previa received blood component therapy (overall 35 patients out of 89, i.e., $39.3 \%$ ), however this variation was not statistically significant. Larger need for blood transfusion in lateral placenta previa may be due to the fact that placental site is very close to uterine arteries. The need for blood transfusion in placenta previa depends upon patient's haemoglobin on admission, which is likely to be low in developing countries.

Zlatnik MG et al. ${ }^{8}$ from United States in their series of 232 cases of placenta previa reported that only $11.8 \%$ of their subjects required blood transfusion. A study from Nigeria reported that the necessity of transfusion was felt in $59.1 \%$ cases of placenta previa. ${ }^{9}$

Rumina $\mathrm{T}$ et al. ${ }^{10}$ studied the need for blood transfusion in 77 subjects with placenta previa in a teaching hospital in Karachi, Pakistan. A total of 177 (mean 2.3) transfusions were received by $59(76.6 \%)$ patients. They also observed that $40.3 \%$ of their patients had haemoglobin less than $8 \mathrm{gm} / \mathrm{dL}$ on arrival and there was also direct proportionality between clinical severity of anemia and mean number of transfusions received by the patients.

The severity of bleeding according to the position of the placenta, whether anterior, posterior or lateral, is poorly studied. Jang DG et al. ${ }^{7}$ conducted a study on 409 patients from Seoul, Korea to elucidate whether the location of placenta below the uterine incision in caesarean section is important in development of bleeding complications. They divided the subjects into two groups; the group whose placenta was located in the anterior portion of the uterus (anterior group) and the group whose placenta was located in the posterior portion of the uterus (posterior group). They reported that in the anterior group, regardless of confounding factors, the incidence of excessive blood loss (OR 2.97; 95\% CI: 1.64-5.37), massive transfusion (OR 3.31; 95\% CI: 1.338.26). However they did not consider the lateral position of the placenta which was taken into consideration in our study.

We had 5 cases of placenta accreta (5.6\%) and all occurred in posterior group. The only 2 caesarean hysterectomies $(2.2 \%)$ which were performed came from these cases of placenta accreta. This is in contrast with findings of Jang DG et al. ${ }^{7}$ who reported higher incidence of adherent placenta and caesarean hysterectomy in anterior placenta compared to posterior placenta previa ( $21.3 \%$ vs. $8.4 \%, 12.4 \%$ vs. $3.2 \%$ respectively). Most of the literature sites that risk of caesarean hysterectomy rise when combination of placenta previa and accreta exists. Usta et al. conducted a comparative study of 22 cases of placental previa with placental accreta and 325 patients without accreta, and concluded that the frequency of maternal complications such as bleeding, blood component therapy, peripartum hysterectomy, etc. is higher in cases with accreta than those cases without accreta.

Atsuko Sekiguchi et al. found higher incidence of preterm delivery in anterior placenta previa (anterior $76.2 \%$, posterior $32.0 \%$ ). They hypothesized that mechanical stimulation of the anterior uterine wall during daily life is more frequent and direct than that of the posterior wall which is protected by the pelvis. However this not proven by background uterine electromyographic activity measured from the abdominal surface in the middle trimester of pregnancy. ${ }^{11}$

Hasegawa et al. ${ }^{12}$ too, while analyzing the ultrasound parameters for emergency cesarean section in placenta previa, reported no statistically significant increased preterm risk with anterior placental position. Our study too did not demonstrate statistically significant difference in preterm delivery in any of the groups.

Tuzovic $\mathrm{L}^{13}$ studied incidence of intrauterine growth restriction in placenta previa according to type and location (complete 15.2\%, incomplete 10.3\%, anterior 
$12.3 \%$ and posterior $10.21 \%$ ) and they opined that neither of these placental site variation influences fetal growth. We too did not much difference in IUGR incidence in different types of placenta previa. Similar observations have been made by Lorie et al. ${ }^{14}$ However, when placental laterality was taken into consideration, 8 of 17 patients $(47.1 \%)$ had IUGR babies, almost two fold increase compared to other groups. As the number was small, so statistical significance could be attached to this observation.

Lucy et al. ${ }^{15}$ studied association between intrauterine growth restriction and second trimester placental location. After adjusting for potential confounders (age, hypertensive disorders of pregnancy), they found that IUGR pregnancies were nearly 4-fold more likely to have lateral placentation in comparison with anterior and posterior placentation. Though there is no clear explanation why IUGR is more likely to occur in lateral placenta, one of the hypothesis is that lateral regions of the uterus may receive less blood flow from single ipsilateral uterine artery whereas, the central regions can derive flow from both uterine arteries and the numerous vascular anastomoses that develop. Lateral placentation may thus predispose to uteroplacental insufficiency and IUGR.

It is generally believed that in spite of significant obstetric bleeding fetal outcome in placenta previa in better compared to other types of obstetric hemorrhage mainly abruptio placenta. There were 4 perinatal deaths (perinatal mortality $4.5 \%$ ) in the present study and 3 of them were intrauterine deaths probably due to severe hypoxia induced by maternal bleeding. A study from Abha, Saudi Arabia has reported $12.7 \%$ perinatal deaths. ${ }^{16}$ This indicates that perinatal mortality in developing countries is significantly high compared to data from western world.

Ananth CV et al. ${ }^{17}$ from USA reported only $1 \%$ perinatal deaths in their study indicating better access to obstetric units in their country.

In summary, it is difficult to attribute specific obstetric complication to a particular type of placenta previa. However, these complications are likely to occur with more frequency compared to general obstetric population. Hence it would be prudent that the treating obstetrician makes all the necessary arrangements before taking the patient with placenta previa for surgery.

\section{ACKNOWLEDGEMENTS}

The authors would like to thank Dr. Pratap Kumar, Dr. Murlidhar Pai, Dr. Jyothi Shetty and Dr. Sapna Amin for their cooperation during the study.

\section{Funding: No funding sources} Conflict of interest: None declared

Ethical approval: The study was approved by the institutional ethics committee

\section{REFERENCES}

1. Dola CP, Garite TJ, Dowling DD, Friend D, Ahdoot D, Asrat T. Placenta previa: does its type affect pregnancy outcome? Am J Perinatol. 2003;20:35360.

2. Bhide A, Prefumo F, Moore J, Hollis B, Thilaganathan B. Placental edge to internal os distance in the late third trimester and mode of delivery in placenta praevia. BJOG. 2003;110:860-4.

3. Bhat SM, HamdiI M, Bhat SK. Placenta previa in a referral hospital in Oman. Saud Med J. 2004;25:72831.

4. Tuzovic L. Complete versus incomplete placenta previa and obstetric outcome. Int J Gynaecol Obstet. 2006;93:110-7.

5. Atsuko Sekiguchi, Akihito Nakai, Ikuno Kawabata, Masako Hayashi, Toshiyuki Takeshita. Type and location of placenta previa affect preterm delivery risk related to antepartum hemorrhage. Int J Med Sci. 2013;10:1683-8.

6. Cho JY, Lee YH, Moon MH, Lee JH. Difference in migration of placenta according to the location and type of placenta previa. J Clin Ultrasound. 2008;36:79-84.

7. Jang DG, We JS, Shin JU, Choi YJ, Ko HS, Park IY, Shin JC. Maternal outcomes according to placental position in placental previa. Int $\mathbf{J}$ Med Sci. 2011;8:439-44.

8. Zlatnik MG, Cheng YW, Norton ME, Thiet MP, Caughey AB. Placenta previa and the risk of preterm delivery. J Matern Fetal Neonatal Med. 2007;20:71923.

9. Ozumba BC, Ezegwui HU. Blood transfusion and caesarean section in a developing country. J Obstet Gynaecol. 2006;26:746-8.

10. Rumina T, Shazia S, Uzma N. Factors related to blood transfusion in placental previa. J Surg Pak (Int). 2012;17:121-5.

11. Grgic O, Matijevic R, Vasilj O. Placental site does not change background uterine electromyographic activity in the middle trimester of pregnancy. Eur $\mathbf{J}$ Obstet Gynaecol Reprod Biol. 2006;127:209-12.

12. Hasegawa J, Matsuoka R, Ichizuka K, Mimura T, Sekizawa A, Farina A, Okai T.. Predisposing factors for massive hemorrhage during cesarean section in patients with placenta previa. Ultrasound Obstet Gynaecol. 2009;34:80-4.

13. Tuzovic L. Complete versus incomplete placenta previa and obstetric outcome. Int J Gynaecol Obstet. 2006;93:110-7.

14. Lorie MH, Anthony OO, George AM, James PC, Allison GC. Effect of placenta previa on foetal growth. Am J Obstet Gynaecol. 2010;203:330-9.

15. Lucy EG, Jessica LI, Vladimir BN, Frisbaek YR, Sonya AR, Joshua AC, Errol RN. Intrauterine growth restriction and placental location. J Ultrasound Med. 2007;26:1481-9.

16. Ahmed Bahar, Abdullah Abusham, Mamodoh Eskandar, Adekkunle Sobande, Mohamed Alsunaidi. 
Risk factors and pregnancy outcome in different types of placenta previa. J Obstet Gynaecol Can. 2009;31(2):126-31.

17. Ananth CV, Smulian JC, Vintzileos AM. The effect of placenta previa on neonatal mortality: a population based study in the United States, 1989 through 1997. Am J Obstet Gynaecol. 2003;188:1305-9.

DOI: $10.5455 / 2320-1770 . i j r \operatorname{cog} 20140930$

Cite this article as: Hebbar SS, Rai L, Zainab R, Guruvare S, Adiga P, Mundkur A. Influence of placental position on obstetric morbidity in placenta previa. Int J Reprod Contracept Obstet Gynecol 2014;3:585-91. 